06.5;05.1

\title{
Модель растворения пор на границах зерен при отжиге ультрамелкозернистого алюминиевого сплава
}

\author{
(C) М.Ю. Гуткин ${ }^{1}$, Т.С. Орлова ${ }^{2}$, Н.В. Скиба ${ }^{1,3, q}$ \\ ${ }^{1}$ Институт проблем машиноведения РАН, Санкт-Петербург, Россия \\ ${ }^{2}$ Физико-технический институт им. А.Ф. Иофффе РАН, Санкт-Петербург, Россия \\ ${ }^{3}$ Санкт-Петербургский политехнический университет Петра Великого, Санкт-Петербург, Россия \\ ๑E-mail: nikolay.skiba@gmail.com
}

Поступило в Редакцию 14 мая 2021 г.

В окончательной редакции 7 июня 2021 г.

Принято к публикации 9 июня 2021г.

\begin{abstract}
Предложена теоретическая модель, описывающая механизм растворения пор на границах зерен в ультрамелкозернистых материалах при длительном отжиге. В рамках модели растворение поры осуществляется за счет испускания вакансий и переползания зернограничных дислокаций вдоль границы зерна к поре. Показано, что при этом происходит существенное понижение полной энергии системы. Результаты модели хорошо согласуются с имеющимися экспериментальными наблюдениями растворения пор при отжиге ультрамелкозернистого сплава $\mathrm{Al}-\mathrm{Zr}$.
\end{abstract}

Ключевые слова: ультрамелкозернистые материалы, поры, зернограничные дисклинации, зернограничные дислокации.

DOI: 10.21883/PJTF.2021.18.51472.18872

Материалы с ультрамелкозернистой (УМЗ) структурой часто обладают высокой прочностью в сочетании с достаточной пластичностью [1]. Известно также, что выделение второй фазы в таких материалах может улучшать их механические характеристики [2]. В экспериментах [3-5] отмечалось ускоренное выделение второй фазы в УМЗ-материалах, полученных методами интенсивной пластической деформации. Например, в алюминиевом УМЗ-сплаве $\mathrm{Al}-\mathrm{Zr}$, полученном методом интенсивной пластической деформации и затем отожженном при температуре $230^{\circ} \mathrm{C}$, наблюдалось значительное количество наноразмерных выделений фазы $\mathrm{Al}_{3} \mathrm{Zr}$ [5]. Однако причины ускоренной кинетики формирования выделений второй фазы в УМЗ-структурах остаются малоизученными. Изучая процесс отжига этого сплава in situ в сканирующем просвечивающем электронном микроскопе, Лефевр и др. [6] обнаружили на начальной стадии отжига, в течение первых $10 \mathrm{~min}$, множественное формирование пор по границам зерен (ГЗ) и их тройным стыкам, которое авторы объяснили перестройкой неравновесных ГЗ с выделением и коагуляцией значительного количества свободного объема. На второй (длительной, в течение $3 \mathrm{~h}$ ) стадии отжига наблюдалось постепенное растворение пор вплоть до полного исчезновения некоторых из них [6]. Такое растворение пор, сопровождаемое эмиссией вакансий, может способствовать ускоренной преципитации в УМЗ-структурах. Для объяснения этого наблюдения авторы [6] предложили теоретическую модель, описывающую растворение поры в тройном стыке ГЗ при длительном отжиге материала. В рамках этой модели зарастание поры, зародившейся, как предполагалось, на стыковой частичной клиновой дисклинации в тройном стыке ГЗ, осуществлялось за счет переползания зернограничных дислокаций (ЗГД) к поре. Заметим, однако, что многие поры, наблюдавшиеся в работе [6], располагались не в тройных стыках ГЗ, а на их прямолинейных участках, так что предложенную авторами модель нельзя, строго говоря, использовать непосредственно для объяснения исчезновения этих пор. Для этого можно соответствующим образом адаптировать модель, предложенную в [6].

Цель настоящей работы заключается в теоретическом описании процесса растворения поры, образовавшейся на частичной клиновой зернограничной дисклинации, в процессе длительного отжига. Идейной основой для этого описания служит модель из работы [6], существенно переделанная и уточненная для случая отдельной ГЗ.

Известно, что при отжиге неравновесные ГЗ (ГЗ, содержащие внесенные ЗГД) переходят в равновесное состояние за счет уменьшения числа этих ЗГД. Снижение плотности внесенных ЗГД обычно связано с их аннигиляцией, испусканием из ГЗ и/или уходом на зернограничные стоки. В качестве таких стоков могут выступать поры, образовавшиеся на ГЗ. В рамках данной модели, как и ранее [6], предполагается, что движущей силой, способствующей зарастанию пор в процессе отжига, является уменьшение плотности внесенных ЗГД в результате их переползания по ГЗ в сторону пор. Переползание ЗГД к поре приводит к ее постепенному зарастанию за счет испускания вакансий, которые диффундируют преимущественно вдоль этой же ГЗ, способствуя переползанию ЗГД к поре. В результате образуется положительная обратная связь: чем большее число ЗГД подходит к порам, тем сильнее падает упру- 

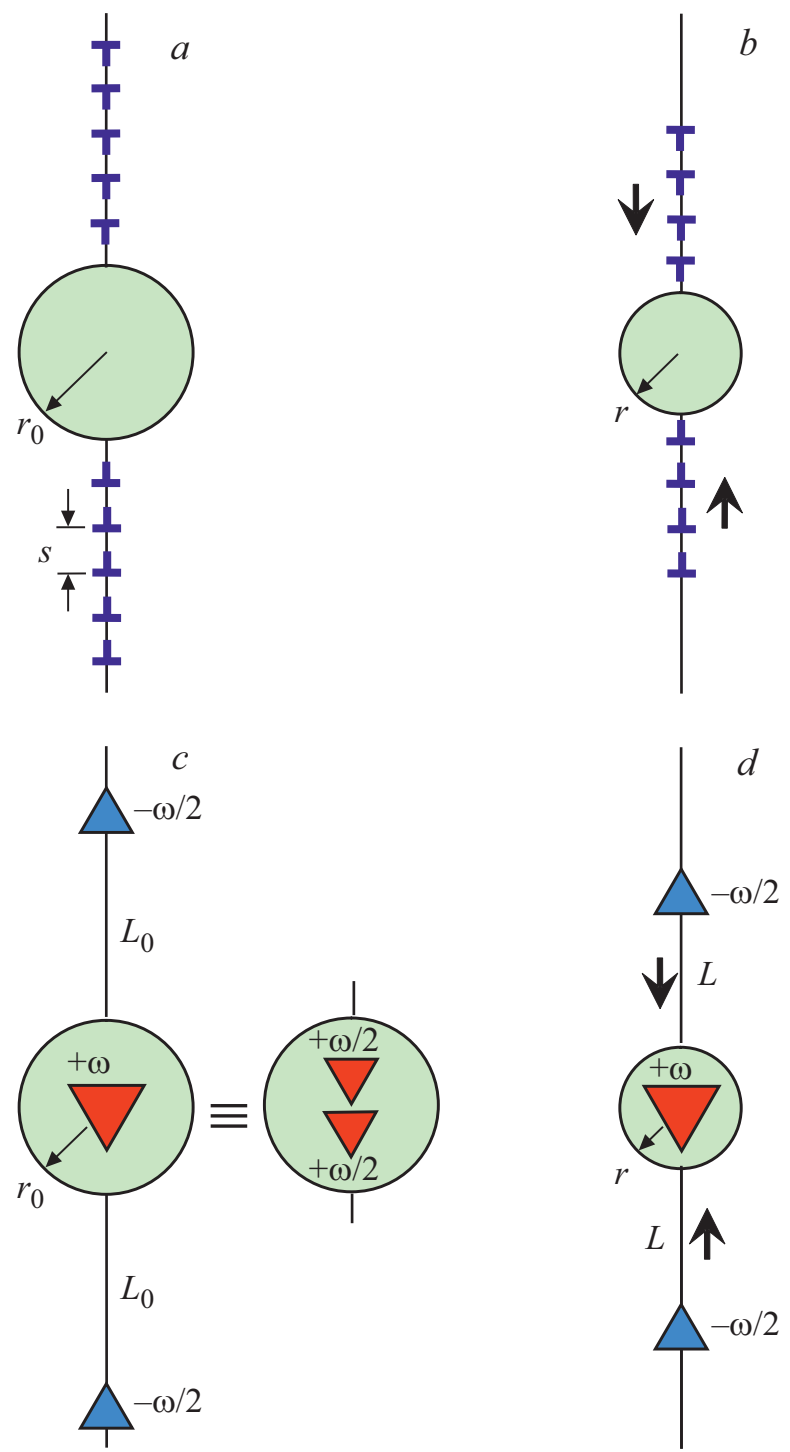

Рис. 1. Модель растворения поры на границе зерна при длительном отжиге в результате переползания к ней внесенных ЗГД. $a-$ исходная конфигурация стенок ЗГД вблизи поры; $b$ - уменьшение поры за счет переползания к ней ЗГД; $c$ - представление стенок внесенных ЗГД в виде линейного дисклинационного квадруполя, состоящего из двух двухосных диполей частичных клиновых дисклинаций с мощностями $\pm \omega / 2$ ( $\pm \omega / 2$-дисклинаций $)$ и плечами $L_{0} ; d-$ зарастание поры в результате уменьшения размера дисклинационного квадруполя $2 L$.

гая энергия зернограничных дисклинаций, на которых зародились поры, и тем выгоднее становится вакансиям испускаться и обеспечивать переползание последующих ЗГД к этим порам.

На рис. 1 показана двумерная модель зарастания поры в результате переползания внесенных ЗГД вдоль ГЗ с порой при длительном отжиге. В исходном состоянии имеется пора радиусом $r_{0}$, зародившаяся на положительной частичной зернограничной дисклинации

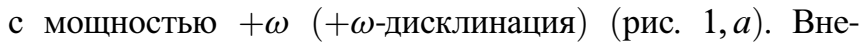

сенные ЗГД изображены в виде двух одинаковых стенок краевых дислокаций противоположных знаков со средним расстоянием $s$ между дислокациями. По мере переползания ЗГД к поре, их поглощения порой и аннигиляции внутри нее происходит уменьшение числа ЗГД и уменьшение радиуса поры $r<r_{0}$ (рис. 1,b). Примыкающие к поре стенки внесенных ЗГД моделируются двумя одинаковыми, но противоположно ориентированными двухосными диполями частичных клиновых дисклинаций [7] мощности $\pm \omega / 2$ ( $\pm \omega / 2$-дисклинации) (рис. $1, c)$, так что модуль суммарной мощности отрицательных $-\omega / 2$-дисклинаций равен величине мощности $+\omega$-дисклинации, расположенной внутри поры. Таким образом, отрицательные - $\omega / 2$-дисклинации вместе с положительной стыковой $+\omega$-дисклинацией образуют два дисклинационных диполя с плечами $L_{0}$ и мощностью $\pm \omega / 2$ ( $\pm \omega / 2$-диполи) (рис. $1, c)$ - линейный дисклинационный квадруполь (ДК) [7]. В этом случае переползание внесенных ЗГД к зарастающей поре эквивалентно уменьшению плеча $L<L_{0}$ этих дисклинационных диполей и общего размера ДК $2 L<2 L_{0}$ (рис. $\left.1, d\right)$.

Рассмотрим энергетические характеристики начального этапа растворения поры в результате уменьшения размера ДК $2 L$ на расстояние $2 p$. В этом случае в предположении, что $L \gg r$, при расчете энергии ДК можно не учитывать влияние на нее свободной поверхности поры. Предположим, что 1) все вакансии, испущенные порой, поглощаются ЗГД; 2) все ЗГД переползают синхронно, сохраняя постоянным период в своих стенках (рис. $1, a, b)$. При уменьшении радиуса поры от начального $r_{0}$ до текущего значения $r$ пора испускает вакансии в количестве $n \approx V / a^{3} \approx \pi\left(r_{0}^{2}-r^{2}\right) / a^{2}$, где $V$ - изменение объема поры в расчете на одну поперечную атомную плоскость толщиной $a$. Распределение этих вакансий равномерно по $2 N=2\left(L_{0}-r_{0}\right) / s$ ЗГД в двух стенках приводит к их синхронному переползанию на расстояние $p \approx a n /(2 N) \approx s\left(r_{0}^{2}-r^{2}\right) / q$, где $q=2 a\left(L_{0}-r_{0}\right) / \pi-$ эффективная площадь поперечного сечения стенки. Отсюда находим, что $r \approx r_{0}\left[1-p q /\left(s r_{0}^{2}\right)\right]^{1 / 2}$. В экспериментах [6] наблюдались зернограничные поры радиуса $r_{0} \approx 30-40 \mathrm{~nm}$. При этом характерные размеры содержащих эти поры ГЗ составляли $L_{0} \approx 200-300 \mathrm{~nm}$. При $a \approx 0.3 \mathrm{~nm}$ получаем, что безразмерный параметр $\beta=q / r_{0}^{2}$ был равен примерно 0.02-0.06. Для случая переползания ЗГД на относительно большое расстояние $($ при $p>s$ ) введем обозначение $m=p / s$. Его целая часть $[m]$ показывает число ЗГД, достигших границы поры, поглощенных ею и аннигилировавших внутри нее. В итоге имеем $r \approx r_{0}(1-0.04 m)^{1 / 2}$, где взято среднее значение $\langle\beta\rangle \approx 0.04$.

Запишем теперь разность энергий $\Delta W$ между текущим состоянием дефектной системы в виде поры радиусом $r$ и ДК размером $2 L=2\left(L_{0}-p\right)$ с полной энергией $W$ и исходным состоянием этой системы с соответствующими параметрами $r_{0}$ и $L_{0}$ и полной энергией $W_{0}$. Переход между этими состояниями энергетически выгоден при выполнении условия $\Delta W=W-W_{0}<0$. 


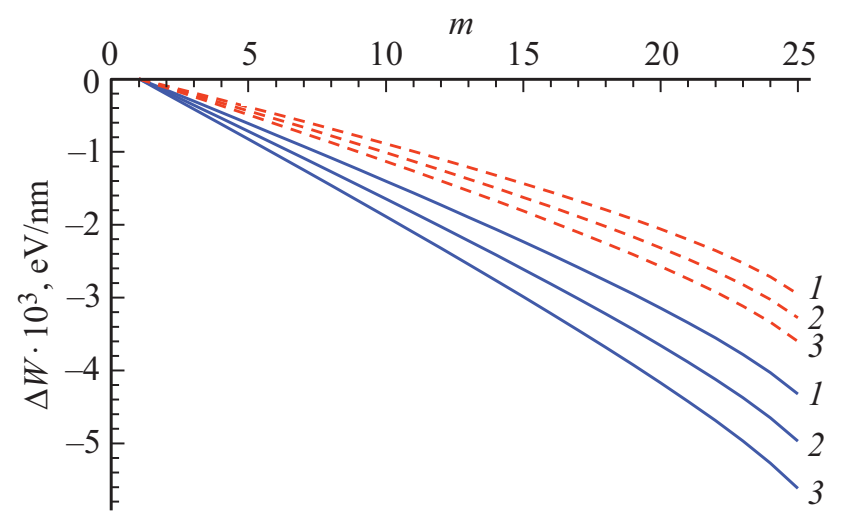

Рис. 2. Зависимость разности энергий $\Delta W$ от числа $m$ ЗГД, поглощенных порой, при $s=0.5 \mathrm{~nm}$ (сплошные кривые) и $1 \mathrm{~nm}$ (штриховые кривые) и разных начальных размерах дисклинационного квадруполя: $2 L_{0}=400(1), 500(2)$ и $600 \mathrm{~nm}(3)$.

Разность энергий $\Delta W$ можно записать в виде

$$
\Delta W=E_{s}+E_{\gamma}+E_{g b}-E_{s 0}-E_{\gamma 0},
$$

где $E_{s} 0=D \omega^{2} L_{0}^{2} \ln 2 / 2$ и $E_{s}=D \omega^{2} L^{2} \ln 2 / 2-$ упругие энергии ДК [7] до и после уменьшения его размера, $E_{\gamma 0}=2 \pi r_{0} \gamma_{s}$ и $E_{\gamma}=2 \pi r \gamma_{s}-$ энергии поверхности поры до и после начала ее зарастания по мере уменьшения размера ДК, $E_{g b}=2 p \gamma_{g b}-$ энергия новых участков ГЗ, появившихся в результате зарастания поры. Здесь $D=G /[2 \pi(1-v)], G-$ модуль сдвига, $v$ - коэффициент Пуассона, $\gamma_{s}$ - удельная энергия поверхности поры, $\gamma_{g b}-$ удельная энергия ГЗ. Тогда с учетом полученной выше зависимости $r(m)$ выражение (1) преобразуется к виду

$$
\begin{aligned}
\Delta W & \approx 2 \gamma_{g b} m s-2 \pi \gamma_{s} r_{0}(1-\sqrt{1-0.04 m}) \\
& -D \omega^{2} m s\left(2 L_{0}-m s\right) \ln 2 / 2
\end{aligned}
$$

С помощью выражения (2) построим численно зависимости изменения энергии $\Delta W$ от числа $m$ ЗГД, на которое уменьшилось количество ЗГД в стенках в результате их поглощения порой и последующей аннигиляции. Расчет проведем на примере УМЗ-сплава $\mathrm{Al}-\mathrm{Zr}$, используя следующие значения параметров материала: $G=27 \mathrm{GPa}, v=0.31, b=0.1 \mathrm{~nm}, \gamma_{s}=1.5 \mathrm{~J} \cdot \mathrm{m}^{-2}$, $\gamma_{g b}=0.5 \mathrm{~J} \cdot \mathrm{m}^{-2}$. Остальные параметры дефектной системы положим равными $r_{0}=40 \mathrm{~nm}, L_{0}=200,250$ и $300 \mathrm{~nm}, \omega \approx b / s, s=0.5$ и $1 \mathrm{~nm}$. Полученные при этих значениях расчетные зависимости $\Delta W(m)$ представлены на рис. 2. Из них видно, что уменьшение размера ДК и соответствующее уменьшение размера поры сопровождаются значительным снижением полной энергии системы.

Таким образом, разработана теоретическая модель, описывающая механизм наблюдавшегося в [6] растворения пор на прямолинейных участках ГЗ в УМЗ-материалах при длительном отжиге. Согласно этой модели, зарастание поры, зародившейся на зернограничной дисклинации, осуществляется путем испускания вакансий, которые мигрируют по ГЗ и поглощаются ЗГД, переползающими за счет поглощения вакансий к поре. На примере УМЗ-сплава $\mathrm{Al}-\mathrm{Zr}$ показана энергетическая выгодность рассмотренного процесса растворения пор. Предложенный механизм растворения пор в УМЗ-материалах хорошо согласуется с имеющимися экспериментальными данными [4-6].

\section{Финансирование работы}

Работа выполнена при частичной поддержке Российского фонда фундаментальных исследований (грант № 19-08-00474), а также (для Н.В. Скибы) Министерства науки и высшего образования РФ (задание № 07842020-0027).

\section{Конфликт интересов}

Авторы заявляют, что у них нет конфликта интересов.

\section{Список литературы}

[1] X. Sauvage, G. Wilde, S.V. Divinski, Z.Horita, R.Z. Valiev, Mater. Sci. Eng. A., 540, 1 (2012). DOI: $10.1016 /$ j.msea.2012.01.080

[2] A. Deschamps, G. Fribourg, Y. Bréchet, J.L. Chemin, C.R. Hutchinson, Acta Mater., 60, 1905 (2012). DOI: 10.1016/j.actamat.2012.01.002

[3] X. Sauvage, A. Duchaussoy, G. Zaher, Mater. Trans., 60, 1151 (2019). DOI: 10.2320/matertrans.MF201919

[4] Y. Nasedkina, X. Sauvage, E.V. Bobruk, M.Yu. Murashkin, R.Z. Valiev, N.A. Enikeev, J. Alloys Compd., 710, 736 (2017). DOI: $10.1016 /$ j.jallcom.2017.03.312

[5] T.A. Latynina, A.M. Mavlyutov, M.Y. Murashkin, R.Z. Valiev, T.S. Orlova, Phil. Mag., 99, 2424 (2019). DOI: $10.1080 / 14786435.2019 .1631501$

[6] W. Lefebvre, N.V. Skiba, F. Chabanais, M.Yu. Gutkin, T.S. Orlova, L. Rigutti, M.Yu. Murashkin, J. Alloys Compd., 862, 158455 (2021). DOI: 10.1016/j.jallcom.2020.158455

[7] В.И. Владимиров, А.Е. Романов, Дисклинации в кристаллах (Наука, Л., 1986). 